\title{
Carbohydrate-Deficient Transferrin to Transferrin Ratio Measurement
}

National Cancer Institute

\section{Source}

National Cancer Institute. Carbohydrate-Deficient Transferrin to Transferrin Ratio

Measurement. NCI Thesaurus. Code C125943.

The determination of the ratio of carbohydrate-deficient transferrin to total transferrin present in a sample. The measurement may be expressed as a ratio or percentage. 